\title{
Increase of CD45-positive Immune Cells in Liver Parenchyma Indicates a More Favorable Prognosis for Patients With Barrett's Cancer
}

\author{
MARIUS KEMPER ${ }^{1}$, TIMO STROHM ${ }^{1}$, KATHARINA GRUPP ${ }^{1}$, TARIK GHADBAN ${ }^{1}$, \\ DEAN BOGOEVSKI ${ }^{1}$, KAI BACHMANN ${ }^{1}$, MAXIMILIAN BOCKHORN ${ }^{1}$, \\ GUIDO SAUTER $^{2}$, JAKOB R. IZBICKI ${ }^{1}$ and MATTHIAS REEH ${ }^{1}$ \\ ${ }^{1}$ Department of General, Visceral and Thoracic Surgery, \\ University Medical Centre Hamburg-Eppendorf, Hamburg, Germany; \\ ${ }^{2}$ Institute of Pathology, University Medical Centre Hamburg-Eppendorf, Hamburg, Germany
}

\begin{abstract}
Background: Despite advances in perioperative management, the 5-year survival rate of patients with esophageal adenocarcinoma (Barrett's cancer) is poor. Adjuvant immunotherapies are currently the subject of clinical trials. The prognostic role of tumor-infiltrating T-lymphocytes (TILs) expressing CD45 has only been investigated in primary tumors. The significance of TILs in the target organs of distant metastases, in particular the liver, is unclear. This study examined the influence of CD45-positive cells in liver parenchyma and primary tumors on cumulative survival. Materials and Methods: The density of CD45-positive cells was analyzed immunohistochemically using tissue microarrays. Sixty-five patients for whom a liver biopsy was available in addition to the primary tumor were included in the study. Liver metastases were found in 21 patients. The results of the immunohistochemical analysis were correlated with patient's outcomes. The Cox proportional hazard model was used to compute mortality hazard ratio in consideration of clinical variables. Results: Elevated density of CD45-positive cells in the liver biopsy corresponded with a better cumulative survival rate $(p<0.001)$, while no significant differences were found for primary tumors. Multivariate Cox regression analysis showed that a high density of CD45-positive cells in the liver parenchyma was an independent prognostic parameter of longer overall survival (hazard ratio $(H R)=0.432, p=0.048$ ). Conclusion: The density of CD45-positive cells in the liver
\end{abstract}

Correspondence to: Matthias Reeh, MD, Department of General, Visceral and Thoracic Surgery, University Medical Centre Hamburg-Eppendorf, Martinistrasse 52, 20246 Hamburg, Germany. E-mail: mreeh@uke.de

Key Words: Esophageal adenocarcinoma, Barret's cancer, CD45, PTPRC, TMA, survival, immune checkpoint inhibition, personalized therapy. parenchyma is an easily measured prognostic biomarker that can identify patient subgroups with a better prognosis. In addition, the density of CD45-positive cells in the liver may assist as a criterion for selecting patients with a high potential for response to adjuvant immunotherapy.

The incidence of adenocarcinoma of the esophagus (Barrett's cancer) has increased across the globe $(1,2)$. Adenocarcinoma of the esophagus is most commonly associated with initial Barrett's esophagus due to gastroesophageal reflux disease (3). In most cases where the curative multimodal approach to treatment is taken, a radical en bloc esophageal resection with radical lymph node dissection is performed with perioperative chemotherapy (4). Depending on the individual tumor type, neoadjuvant therapy may make sense (5). In recent years, it has been possible to reduce postoperative mortality and morbidity through improved perioperative management, the development of minimally invasive techniques, and the centralization of specialized centers. Despite this technical progress, the 5-year survival rate remains low at less than $15 \%$. Thus, innovative therapies are urgently needed (6).

Tumor growth behavior is determined not only by tumor biology, but also by the immune reaction of the host. This consists of humoral and cellular components and interaction with the tumor cells and tumor stroma. In recent years immunotherapy has seen substantial advancement with immune checkpoint inhibition in the treatment of solid tumors, especially malignant melanoma $(7,8)$. The efficacy of programmed cell death protein 1 (PD1) blockade for adenocarcinoma of the esophagus is presently the aim of clinical trials (9-11). The current challenge lies in using biomarkers to identify which patients would respond to adjuvant immunotherapy.

CD45 (protein tyrosine phosphatase, receptor type C; PTPRC) is a pan-leukocyte marker that is simple to measure. This signaling molecule is an important regulator of T- and B-cell antigen receptor signaling. Activated, memory and 
cytotoxic tumor-infiltrating T-lymphocytes (TILs) belong to the cellular mechanisms of the immune reaction and express CD45 on their cell surface (12).

The aim of our study was to investigate the influence of CD45-positive immune cells in liver parenchyma and primary tumors on the prognosis of patients with adenocarcinoma of the esophagus.

\section{Materials and Methods}

Study design and patients. A group of 65 patients who underwent radical en bloc esophageal resection with radical lymph node dissection with metachronous or synchronous liver biopsy at the University Medical Centre Hamburg-Eppendorf between 1992 and 2009 were included in this study. Of these patients, $56(86 \%)$ were male and nine (14\%) female. Ongoing follow-up data were available for 60 patients. The mean age of patients at time of surgery was 63.4 years; none of the patients received neoadjuvant therapy and all patients underwent surgery for curative purposes. Tumor stage and degree of differentiation were classified according to the seventh edition of the TNM Classification of Malignant Tumours published by the Union for International Cancer Control (UICC) (13). All tumor stages ranging from carcinoma in situ to advanced stages with distant metastases were included. Liver biopsies were performed to rule out or confirm metastases. Liver metastases were found in 21 patients, while the suspicion of liver metastases was not confirmed in 44 patients.

The use of the tissue samples in this study was approved by the Ethics Committee of the Hamburg Chamber of Physicians (approval number: PV3548) and written consent was obtained from the patients.

Tissue microarray (TMA) construction. The tissue punches were taken from patients with histologically confirmed adenocarcinoma of the esophagus. The areas of the primary tumors and suspected liver metastases were marked on hematoxylin and eosin-stained tissue sections of the samples. These marked tissue sections served to indicate the sites for making sampling from the donor paraffin blocks. TMA construction was performed as described previously (14). The tissue punches $(0.6 \mathrm{~mm}$ diameter $)$ were taken from the marked regions using a custom-made precision instrument (Beecher Instruments, Silver Spring, MD, USA). Tissue cylinders from each of the 65 primary tumors with liver biopsy and liver parenchyma were inserted into the $25 \times 35 \mathrm{~mm}$ paraffin block to create the TMA used in this study. The TMA block was cut into 4- $\mu \mathrm{m}$ sections and mounted on slides using Paraffin Sectioning Aid System (Instrumedics, Hackensack, NJ, USA).

Immunohistochemistry and analysis. CD45 was marked immunohistochemically on the TMA sections. Briefly, after antigen retrieval of the deparaffinized tissue sections, the primary antibody to CD45 (Abcam, Cambridge, UK) was used according to the manufacturer's instructions. All samples were incubated overnight at $4^{\circ} \mathrm{C}$. Staining was performed according to the labeled (strept)avidin-biotin method (HRP-AEC System; R\&D Systems, Minneapolis, MN, USA). Evaluation of the density of CD45-positive cells within the spots on the stained TMA sections was carried out using light microscopy. Differentiation was made between the following cell densities: none (score 0 ), low (score 1), moderate (score 2) and high (score 3). For
Table I. Clinical and pathological characteristics of the patients according to the density of CD45-positive cells.

\begin{tabular}{|c|c|c|c|}
\hline \multirow[b]{2}{*}{ Characteristic } & \multicolumn{2}{|c|}{$\mathrm{CD} 45, \mathrm{n}(\%)$} & \multirow[b]{2}{*}{$p$-Value } \\
\hline & $\begin{array}{c}\text { Low } \\
(\mathrm{n}=14)\end{array}$ & $\begin{array}{l}\text { High } \\
(\mathrm{n}=40)\end{array}$ & \\
\hline \multicolumn{4}{|l|}{ Gender } \\
\hline Female & $2(3.7 \%)$ & $7(13.0 \%)$ & \multirow[t]{2}{*}{0.781} \\
\hline Male & $12(22.2 \%)$ & $33(61.1 \%)$ & \\
\hline \multicolumn{4}{|l|}{ Tumor stage } \\
\hline pT1 & $1(2 \%)$ & $11(22 \%)$ & \multirow[t]{4}{*}{0.104} \\
\hline pT2 & $3(6 \%)$ & $11(22 \%)$ & \\
\hline pT3 & $8(16 \%$ & $15(30 \%)$ & \\
\hline pT4 & $1(2 \%)$ & $0(0 \%)$ & \\
\hline \multicolumn{4}{|c|}{ Lymph node metastasis } \\
\hline pNO & $2(4.2 \%)$ & $16(33.3 \%)$ & \multirow[t]{3}{*}{0.081} \\
\hline $\mathrm{pN} 1$ & $11(22.9 \%)$ & $18(37.5 \%)$ & \\
\hline $\mathrm{pN} 2$ & $0(0 \%)$ & $1(2.1 \%)$ & \\
\hline \multicolumn{4}{|c|}{ Distant metastasis } \\
\hline M0 & $1(1.8 \%)$ & $36(65.5 \%)$ & \multirow[t]{2}{*}{$<0.001$} \\
\hline M1 & $13(23.6 \%)$ & $5(9.1 \%)$ & \\
\hline \multicolumn{4}{|c|}{ Residual tumor } \\
\hline R0 & $6(11.5 \%)$ & $33(63.5 \%)$ & \multirow[t]{3}{*}{0.002} \\
\hline $\mathrm{R} 1$ & $3(5.8 \%)$ & $4(7.7 \%)$ & \\
\hline $\mathrm{R} 2$ & $5(9.6 \%)$ & $1(1.9 \%)$ & \\
\hline \multicolumn{4}{|l|}{ Grading } \\
\hline 1 & $0(0 \%)$ & $3(6 \%)$ & \multirow[t]{3}{*}{0.404} \\
\hline 2 & $4(8 \%)$ & $16(32 \%)$ & \\
\hline 3 & $9(18 \%)$ & $18(36 \%)$ & \\
\hline \multicolumn{4}{|c|}{ UICC* classification } \\
\hline I & $0(0 \%)$ & $5(11.9 \%)$ & \multirow[t]{4}{*}{$<0.001$} \\
\hline II & $0(0 \%)$ & $10(23.8 \%)$ & \\
\hline III & $1(2.3 \%)$ & $6(14.3 \%)$ & \\
\hline IV & $13(31.0 \%)$ & $7(16.7 \%)$ & \\
\hline
\end{tabular}

*UICC: Union for International Cancer Control (13).

further analysis, cell densities with scores of 0 and 1 were summarized as low CD45 density and spots with scores of 2 and 3 as high CD45 density. This evaluation was carried out by two experienced investigators without knowledge of the patient data.

Statistical analysis. For statistical analysis SPSS 22 (IBM, Armonk, NY, USA) was applied. Descriptive statistics were used to describe patient baseline characteristics. Correlations between parameters were performed using Pearson's correlation for continuous variables, and for discrete variables the Chi-square test or Fisher's exact test was used. Events considered for survival analysis were death due to cancer diagnosis. When no event was recorded, the patients were censored at the last contact for statistical evaluation. Survival curves for overall survival of the patients were plotted (Kaplan-Meier method) and analyzed by implementing the log-rank test. Results are presented as median survival in months with $95 \%$ confidence interval (CI) and number of patients at risk. The overall survival (OS) was computed as the time period from the date of surgery to either the date of death or last follow-up, whichever occurred first. The Cox proportional hazards model was used to examine multiple variables in one model, using low CD45 density as baseline hazard 
A

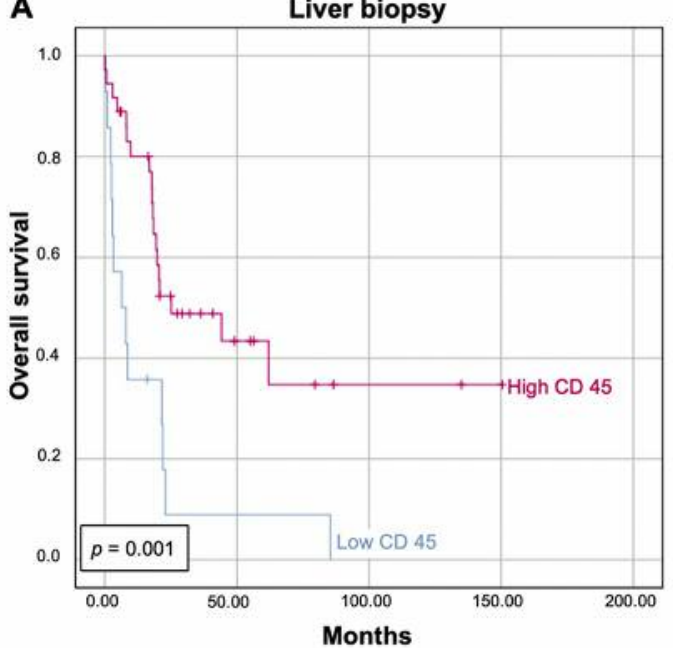

B

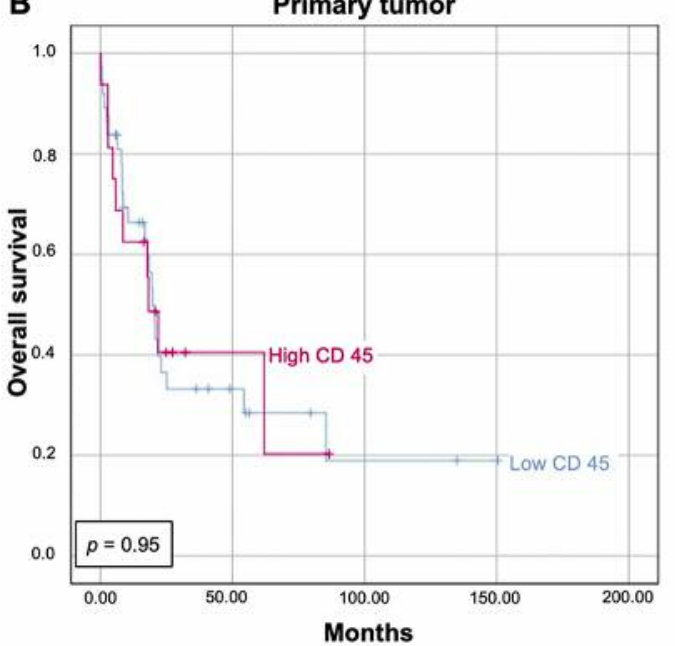

Figure 1. Analysis of overall survival in histologically confirmed adenocarcinoma of the esophagus with synchronous or metachronous liver biopsy. Survival is shown according to the density of CD45-positive cells in the liver biopsy (A) and primary tumor (B). Differentiation was made between low and high density of CD45-positive cells. A high density of CD45-positive cells in the liver biopsy significantly corresponded with improved cumulative survival $(p=0.001)$, while no significant association was found for primary tumors. Each tick mark represents one patient censored. p-Values were calculated by log-rank tests.

of 1.0. In this analysis the variables age, gender, $\mathrm{pT}, \mathrm{pN}$, and resection status were included. Statements of significance refer to $p$ values of two-tailed tests that were less than 0.05 .

\section{Results}

The prepared TMA encompassed samples from 65 primary tumors and 65 liver biopsies, in 21 of which liver metastases were confirmed. Only samples with discernible immunohistochemical results were included in the analysis. The median age of the patients was 63.4 years. Clinicopathological associations of the CD45-positive cell density are summarized in Table I. Briefly, patients with a high density of CD45-positive cells in the liver samples less frequently had distant metastasis (pM). Moreover, a high CD45-positive cell density was associated with a lower UICC classification. R2 resections were more frequent in patients with low density of CD45-positive cells in the liver sample. No significant differences in CD45 density with regard to gender, $\mathrm{pT}, \mathrm{pN}$ and grading were found.

A statistically significant difference was seen for the liver biopsy in regard to cumulative survival depending on the extent of CD45-positive cells in the liver biopsy. Patients with high density of CD45-positive cells in the liver biopsy had a statistically significant longer time of survival ( $p=0.001$; Figure 1A). The median survival of patients with low density of CD45-positive cells in the liver sample was 6.4 months, whereas patients with high CD45-positive cell density had a prolonged median survival of 25.2 months. No significant differences concerning length of survival in
Table II. Multivariable analysis of CD45-positive cell density, age, sex, tumor stage ( $p T)$, lymph node metastasis $(p N)$ and residual tumor $(R)$.

\begin{tabular}{llcc}
\hline & & HR $(95 \% \mathrm{CI})$ & $p$-Value \\
\hline CD45 & Low vs. high & 0.432 & 0.048 \\
Gender & Female vs. male & 1.583 & 0.419 \\
Age & Year increase & 0.999 & 0.949 \\
pT & Category increase & 1.469 & 0.175 \\
pN & Category increase & 1.653 & 0.277 \\
R & Category increase & 1.504 & 0.248 \\
\hline
\end{tabular}

CI: Confidence interval; HR: hazard ratio.

connection with density of CD45-positive cells of primary tumors was found (Figure 1B).

Multivariate Cox regression analysis showed that a high density of CD45-positive cells in the liver parenchyma was an independent prognostic parameter of longer overall survival (hazard ratio $=0.432, p=0.048$ ) $($ Table II).

\section{Discussion}

Adenocarcinoma of the esophagus is an aggressive malignant tumor of increasing significance and has often already metastasized at time of diagnosis. Tumor progression of esophageal adenocarcinoma is influenced not only by tumor biology, but also by the immune reaction of the host (15). The aim of our study was to evaluate a correlation between survival and the number of inflammatory cells in the liver parenchyma 
and primary tumor. The pan-inflammatory cell marker CD45 was immunohistochemically stained on the TMA created for this study. Here, CD45 antibody was used to detect tumorinfiltrating, activated memory and cytotoxic T-lymphocytes (TILs), as before (16). The underlying assumption is that the presence of TILs in the tumor environment and within the primary tumor or metastasis lead to a quicker and more effective immune reaction to the expressed tumor antigens. A differentiation between intratumoral and peritumoral infiltrating inflammatory cells did not appear worthwhile, because of the small section in the TMA punches used for the study. In accordance with recently published studies, the stained immune cells were evaluated as being tumor-associated because their presence in the tissue most probably was induced by disseminated tumor cells (17). In addition, CD45 is not expressed in normal liver parenchyma (18).

The results showed that patients with high density of CD45positive immune cells in the examined liver parenchyma had a significantly longer length of survival ( $p=0.001$, Figure 1A), while there was no significant influence of the density of CD45-positive cells in the primary tumor on length of survival (Figure 1B). The strong correlation of a greater number of CD45-positive cells with favorable prognosis was confirmed by the Cox proportional hazard model. Our data postulate that T-cells expressing CD45 in the liver tissue inhibit micrometastasis and ultimately extend patient survival.

Similar observations have been made concerning histological examination of the local immune reaction to other tumors of the gastrointestinal tract, indicating that tumor infiltration with CD45-positive TILs is associated with a benefit for patients with gastric and colorectal cancer $(19,20)$.

In previous studies on Barrett's cancer, it has been shown that having a low number of intratumoral CD45-positive immune cells was an unfavorable risk factor for disease-free survival in patients with UICC stages I-IIa. In the case of other advanced carcinomas (stages IIb-IV), the study by von Rauser et al. showed no correlation between survival and CD45-positive immune cells in the primary tumor (16). This allows the conclusion that TILs in the early primary tumor stage are of great importance, but that as the disease progresses, less immunogenic tumor cell clones assert themselves and the significance of TILs in the primary tumor declines. However, the data here show that CD45-expressing T-cells in the liver parenchyma have a positive influence on patient survival regardless of primary tumor stage.

In recent years, substantial advancement has been seen in immunotherapy, with immune checkpoint inhibition in the treatment of solid tumors, especially malignant melanoma $(8$, 10). The correlation between the density of TILs and the response to immunotherapeutic active substances is of growing interest for the purpose of identifying which patients will profit most from immunotherapy and determining the optimal point in time for therapy.
PD1 and programmed cell death 1 ligand 1 (PD-L1) are critical immune checkpoint molecules that negatively affect T-cell activation $(21,22)$. The antibody-mediated blockade of PD1/PD-L1 effectively increases T-cell activity and consequently the antitumor immune response (8). The antibody-mediated blockade of these molecules has shown remarkable efficacy against malignant melanoma, non-small cell bronchial carcinoma and kidney cell carcinoma, and is already being used in the clinical setting $(8,23-26)$.

In regard to Barrett's cancer, Loss et al. demonstrated that high PD-L1 expression is associated with a poor chance of survival (23). The efficacy of PD1 blockade for esophageal adenocarcinoma is presently the subject of clinical trials (10, $24,25)$. The current challenge in clinical practice when using PD1 blockade in esophageal carcinoma lies not only in increasing its efficacy by combining it with surgical resection, chemotherapy, radiation therapy and other biological agents, but also in identifying those patients who will most benefit from adjuvant immunotherapy in terms of a personalized therapy (26). The density of CD45-positive cells in the liver parenchyma is an easily measured prognostic biomarker that can identify subgroups of patients with a better prognosis. In addition, density of CD45-positive cells in the liver can assist as a criterion for selecting patients with great potential for response to adjuvant immunotherapy.

\section{Additional Information}

Ethics approval and consent to participate: The use of the tissue samples in this study was approved by the Ethics Committee of the Hamburg Chamber of Physicians and written consent was obtained from the patients. The study was performed in accordance with the Declaration of Helsinki.

\section{Conflict of Interest}

All Authors declare no conflict of interest in regard to this study.

\section{Availability of Data and Material}

Additional data and material are available upon request.

\section{Funding}

This research received funding from the University Medical Centre Hamburg-Eppendorf.

\section{Authors' Contributions}

M.K., M.R., D.B. and M.B. developed the concept and designed experiments. T.S. and K.G. performed the experiments. T.S., K.G., M.K., M.R. and T.G. collected and analyzed the data. M.K. and M.R. wrote the article. J.I., G.S. and K.B. gave technical support and conceptional advice. All Authors contributed extensively to the work presented here. 


\section{Acknowledgements}

The Authors thank the employees of the Institute of Pathology for constant technical and organizational support.

\section{References}

1 Pera M, Cameron AJ, Trastek VF, Carpenter HA and Zinsmeister AR: Increasing incidence of adenocarcinoma of the esophagus and esophagogastric junction. Gastroenterology 104: 510-513, 1993. PMID: 8425693. DOI: 10.1016/0016-5085(93)90420-H.

2 Ferlay J, Soerjomataram I, Dikshit R, Eser S, Mathers C, Rebelo M, Parkin DM, Forman D and Bray F: Cancer incidence and mortality worldwide: Sources, methods and major patterns in GLOBOCAN 2012. Int J Cancer 136: E359-E386, 2014. PMID: 25220842. DOI: $10.1002 / \mathrm{ijc} .29210$.

3 DeMeester SR: Adenocarcinoma of the Esophagus and Cardia: A Review of the Disease and Its Treatment. Ann Surg Oncol 13: 12-30, 2006. PMID: 16378161. DOI: 10.1245/ASO.2005.12.025.

4 Cunningham D, Allum WH, Stenning SP, Thompson JN, Van de Velde CJH, Nicolson M, Scarffe JH, Lofts FJ, Falk SJ, Iveson TJ, Smith DB, Langley RE, Verma M, Weeden S, Chua YJ and MAGIC Trial Participants: Perioperative chemotherapy versus surgery alone for resectable gastroesophageal cancer. N Engl J Med 355: 11-20, 2006. PMID: 16822992. DOI: 10.1056/ NEJMoa055531.

5 Porschen R, Buck A, Fischbach W, Gockel I, Görling U, Grenacher L, Hollerbach S, Hölscher A, Körber J, Messmann H, Meyer HJ, Miehlke S, Möhler M, Nöthlings U, Pech U, Schmidberger H, Schmidt M, Stahl M, Stuschke M, ThussPatience P, Trojan J, Vanhoefer U, Weimann A, Wenz F, Wullstein C: S3-Leitlinie Diagnostik und Therapie der Plattenepithelkarzinome und Adenokarzinome des Ösophagus. Z Gastroenterol 53(11): 1288-1347, 2015. PMID: 26562403. DOI: 10.1055/s-0041-107381.

6 Markar S, Gronnier C, Duhamel A, Bigourdan J-M, Badic B, Rieu du MC, Lefevre JH, Turner K, Luc G and Mariette C: Pattern of postoperative mortality after esophageal cancer resection according to center volume: results from a large european multicenter study. Ann Surg Oncol 22: 2615-2623, 2015. PMID: 25605511. DOI: 10.1245/s 10434-014-4310-5.

7 Wolchok J: How recent advances in immunotherapy are changing the standard of care for patients with metastatic melanoma. Ann Oncol 23(Suppl 8): viii15-21, 2012. PMID: 22918923. DOI: $10.1093 /$ annonc/mds 258 .

8 Topalian SL, Hodi FS, Brahmer JR, Gettinger SN, Smith DC, McDermott DF, Powderly JD, Carvajal RD, Sosman JA, Atkins MB, Leming PD, Spigel DR, Antonia SJ, Horn L, Drake CG, Pardoll DM, Chen L, Sharfman WH, Anders RA, Taube JM, McMiller TL, Xu H, Korman AJ, Jure-Kunkel M, Agrawal S, McDonald D, Kollia GD, Gupta A, Wigginton JM and Sznol M: Safety, activity, and immune correlates of anti-PD-1 antibody in cancer. N Engl J Med 366: 2443-2454, 2012. PMID: 22658127. DOI: $10.1056 /$ NEJMoa1200690.

9 Chung HC, Arkenau H-T, Wyrwicz L, Oh D-Y, Lee K-W, Infante JR, Chin KM, Heydebreck von A, Kang Y-K and Safran H: Safety, PD-L1 expression, and clinical activity of avelumab (MSB0010718C), an anti-PD-L1 antibody, in patients with advanced gastric or gastroesophageal junction cancer. J Clin Oncol 34: 167, 2016. DOI: 10.1200/jco.2016.34.4_suppl.167.
10 Bang Y-J, Cho JY, Kim YH, Kim JW, Di Bartolomeo M, Ajani JA, Yamaguchi K, Balogh A, Sanchez T and Moehler M: Efficacy of sequential ipilimumab monotherapy versus best supportive care for unresectable locally advanced/metastatic gastric or gastroesophageal junction cancer. Clin Cancer Res 23: 5671-5678, 2017. PMID: 28655793. DOI: 10.1158/1078-0432.CCR-17-0025.

11 Myint ZW and Goel G: Role of modern immunotherapy in gastrointestinal malignancies: A review of current clinical progress. J Hematol Oncol 10: 86, 2017. PMID: 28434400. DOI: 10.1186/s 13045-017-0454-7.

$12 \mathrm{Hu} \mathrm{G}$ and Wang S: Tumor-infiltrating CD45RO+ Memory Tlymphocytes predict favorable clinical outcome in solid tumors. Sci Rep 7: 10376, 2017. PMID: 28871164. DOI: 10.1038/s41598017-11122-2.

13 Sobin LH, Gospodarowicz MK and Wittekind C: TNM Classification of Malignant Tumors. Seventh Edition. Hoboken, NJ, USA, John Wiley \& Sons, Inc., 2010.

14 Kononen J, Bubendorf L, Kallionimeni A, Bärlund M, Schraml P, Leighton S, Torhorst J, Mihatsch MJ, Sauter G and Kallionimeni O-P: Tissue microarrays for high-throughput molecular profiling of tumor specimens. Nat Med 4: 844-847, 1998. PMID: 9662379.

15 Lin EW, Karakasheva TA, Hicks PD, Bass AJ and Rustgi AK: The tumor microenvironment in esophageal cancer. Oncogene 35: 5337-5349, 2016. PMID: 26923327. DOI: 10.1038/onc.2016.34.

16 Rauser S, Langer R, Tschernitz S, Gais P, Jütting U, Feith M, Höfler $\mathrm{H}$, Walch A: High number of CD45RO+ tumor infiltrating lymphocytes is an independent prognostic factor in non-metastasized (stage I-IIA) esophageal adenocarcinoma. BMC Cancer 10: 608, 2010. PMID: 21054833. DOI: 10.1186/1471-2407-10-608.

17 Ugolini C, Basolo F, Proietti A, Vitti P, Elisei R, Miccoli P and Toniolo A: Lymphocyte and immature dendritic cell infiltrates in differentiated, poorly differentiated, and undifferentiated thyroid carcinoma. Thyroid 17: 389-393, 2007. PMID: 17542668. DOI: $10.1089 /$ thy.2006.0306.

18 Uhlén M, Fagerberg L, Hallström BM, Lindskog C, Oksvold P, Mardinoglu A, Sivertsson Å, Kampf C, Sjöstedt E, Asplund A, Olsson I, Edlund K, Lundberg E, Navani S, Szigyarto CA-K, Odeberg J, Djureinovic D, Takanen JO, Hober S, Alm T, Edqvist P-H, Berling H, Tegel H, Mulder J, Rockberg J, Nilsson P, Schwenk JM, Hamsten M, Feilitzen von K, Forsberg M, Persson L, Johansson F, Zwahlen M, Heijne von G, Nielsen J and Pontén F: Proteomics. Tissue-based map of the human proteome. Science 347: 1260419-1260419, 2015. PMID: 25613900. DOI: 10.1126/science.1260419.

19 Lee HE, Chae SW, Lee YJ, Kim MA, Lee HS, Lee BL and Kim WH: Prognostic implications of type and density of tumourinfiltrating lymphocytes in gastric cancer. Br J Cancer 99: 17041711, 2008. PMID: 18941457. DOI: 10.1038/sj.bjc.6604738.

20 Pagès F, Berger A, Camus M, Sanchez-Cabo F, Costes A, Molidor R, Mlecnik B, Kirilovsky A, Nilsson M, Damotte D, Meatchi T, Bruneval P, Cugnenc PH, Trajanoski Z, Fridman WH and Galon J: Effector memory T-cells, early metastasis, and survival in colorectal cancer. N Engl J Med 353(25): 2654-2666, 2005. PMID: 16371631. DOI: 10.1056/NEJMoa051424.

21 Iwai Y, Ishida M, Tanaka Y, Okazaki T, Honjo T and Minato N: Involvement of PD-L1 on tumor cells in the escape from host immune system and tumor immunotherapy by PD-L1 blockade. Proc Natl Acad Sci 99: 12293-12297, 2002. PMCID: PMC129438. DOI: 10.1073/pnas.192461099. 
22 Leach DR, Krummel MF and Allison JP: Enhancement of antitumor immunity by CTLA-4 blockade. Science 271: 17341736, 1996. PMID: 8596936.

23 Loos M, Langer R, Schuster T, Gertler R, Walch A, Rauser S, Friess $\mathrm{H}$ and Feith $\mathrm{M}$ : Clinical significance of the costimulatory molecule B7-H1 in Barrett carcinoma. Ann Thorac Surg 91: 1025-1031, 2011. PMID: 21440117. DOI: 10.1016/j.athoracsur.2010.12.041.

24 Chung HC, Arkenau HT, Wyrwicz L, Oh DY, Lee KW, Infante JR, Chin K, Heydebreck Von A, Kang YK and Safran H: 2364 Avelumab (MSB0010718C), an anti-PD-L1 antibody, in patients with advanced gastric or gastroesophageal junction cancer: A phase Ib trial. Eur J Cancer 51: S457, 2015. DOI: 10.1200/jco.2016. 34.4_suppl.167.

25 Janjigian YY, Adenis A, Aucoin J-S, Barone C, Boku N, Chau I, Cleary JM, Feeney K, Franke FA, Moehler M, Roca EL, Schenker M, Li M and Ajani JA: Checkmate 649: A randomized, multicenter, open-label, phase 3 study of nivolumab (Nivo) plus ipilimumab (Ipi) versus oxaliplatin plus fluoropyrimidine in patients (Pts) with previously untreated advanced or metastatic gastric (G) or gastroesophageal junction (GEJ) cancer. J Clin Oncol 35: TPS213TPS213, 2017. DOI: 10.1200/JCO.2017.35.4_suppl.TPS213.

26 Tanaka T, Nakamura J and Noshiro H: Promising immunotherapies for esophageal cancer. Expert Opin Biol Ther 17: 723-733, 2017. PMID: 28366014. DOI: 10.1080/14712598.2017.1315404.

Received January 21, 2019

Revised February 4, 2019

Accepted February 11, 2019 